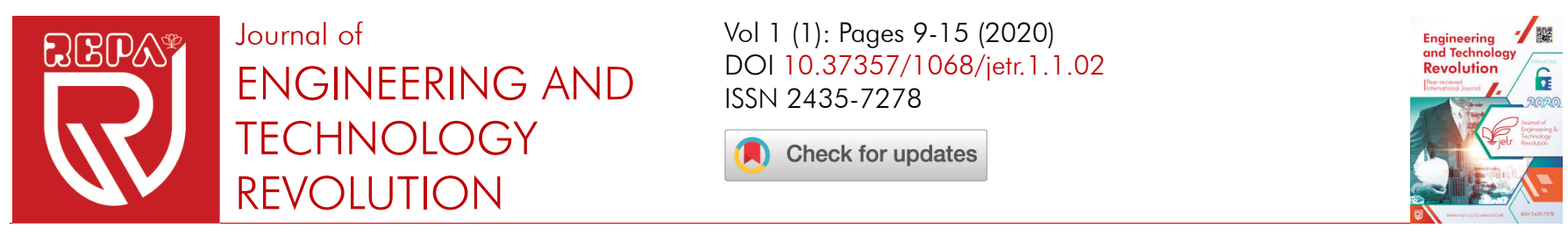

\title{
Active substation design for distributed generation integration in Afghanistan's grid
}

\author{
Ali Jan Joya ${ }^{1}$ and Habiburahman Shirani ${ }^{2}$ \\ ${ }^{1}$ Ministry of Energy and Water, Kabul, Afghanistan \\ ${ }^{2}$ Department of Electrical and Electronics Engineering, Faculty of Engineering, Kabul University, Kabul, Afghanistan
}

\section{Special Issue Article Open Access Published}

Keywords

- Active substation

- Distributed generation

- Phase shifting transformer

- STATCOM

- Afghanistan power system

\section{ABSTRACT}

Energy has been harvested from water, wind and solar as isolated distributed generation (DG) to electrify rural households and villages in Afghanistan. Several solar PV and wind farms have been or planned to be built as isolated distributed generators in those provinces that have no access to national grid. While it is ideal that the national electrical grid be extended to those provinces and regions, these distributed generators are not compatible with the operating voltage specifications of the national grid. In this study, we have focused on changing the topology of distribution grid at the planning and design stage by introducing active devices to control voltage, especially in the weak nodes of the grid. At substations which convert DG to MV/LV, using two active devices such as On Load Tap ChangingPhase Shifting Transformer (OLTC-PST) and Static Synchronize Compensator (STATCOM) should be considered in the design. The integration a 1-MW wind power distributed generator in Panjshir province of Afghanistan with the national grid network is considered. Introducing these active devices that increases the installed DG power in weak networks is analyzed. An operation and control strategy for the Active Substation is verified by temporal power flow simulations. The results show that using these active devices can increase the active power injection capability in weak networks.

\section{Introduction}

Afghanistan is historically an energy-deficient country despite having enormous renewable energy resources such as hydro, wind, solar, biomass and geothermal [1,2]. With the help of the international community, the government of Afghanistan has attempted to resolve the problem of electricity distribution; however, $30 \%$ of the total population has access to electricity. In the rural areas where almost $70 \%$ of Afghanistan population live, less than $10 \%$ have access to the national power grid. Afghanistan imports $87 \%$ of electrical energy from its neighbor countries (Uzbekistan, Turkmenistan, Tajikistan, and Iran) , and the remaining 13\% from its own sources, mainly hydro [3].

Renewable energy sources in Afghanistan have not been uniformly distributed throughout the country except solar energy. Western provinces and regions with high altitude are good for wind energy generation, whereas central, northern, southern and eastern regions are suitable for small and micro hydropower [4]. In some regions and villages, electrical energy has been harvested from renewable energy resources such as solar, wind, and micro hydro as isolated distributed generators by NGOs, the Ministry of Rural Rehabilitation and Development, and the Ministry of Energy and Water [3]. However, integrating these isolated distributed generators into national power grid has not been considered, limiting any effort to extend the national grid into these remote regions and villages.

In this study, we consider the integration of an isolated operating wind energy DG station into the national power grid in Panjshir province of Afghanistan by utilizing active devices to connect to the MV/LV substation. The studied active devices are On Load Tap Changing - Phase Shafting Transformer (OLTC-PST) and Static Synchronous Compensator (STATCOM). The contribution of these active devices increases the DG power penetration in weak networks. Phase-shifting transformers are employed for voltage regulation while STATCOM is used for reactive power compensation [5-10]. An operation and control strategy for the Active Substation is verified by temporal power flow simulations. The results show that making the substation an active substation using the active devices increases the active power injection capability in weak networks.

\section{Problem Statement}

Network topology is changing due to DG-friendly policies that aim to increase use of renewable energies, subsidize the electricity produced by renewable sources, and liberalize electricity markets $[5,11,12]$. However, the current electrical grid is unable to absorb the maximum-available DG power, making integration a significant challenge since available DG power cannot be injected freely into the network if the distribution network (grid) in passive $[13,14]$. In some provinces in Afghanistan, electricity has been harvested from renewable energy sources such solar, wind and micro hydro as isolated generators [4]. However, neither the national grid planners nor the DG implementers seem to be contemplating the challenges to integrate the DG renewable sources into the national power grid. 
In Panjshir province of Afghanistan, an isolated 1-MW wind farm generator services nearby villages. The Ministry of Energy and Water has planned to extend to Panjshir the national power grid with its total energy capacity of 32 MW [3]. However, if a passive substation is built, it could not integrate the renewable energy into the distribution network.

\section{Solution mechanism}

For solving the problem, we suggest changing the topology of substation by using two active devices such as On Load Tap Changing Phase Shifting Transformer (OLTCPST) and Static Synchronous Compensator (STATCOM). This scenario should also be considered in other regions in Afghanistan by grid planners. The solution is confirmed by results of the MATLAB/Simulink simulation described here.

\section{Methodology}

The methodology used in this study is composed of a theoretical system simulation where a DG source is connected to a MV/LV transformer substation through a lowvoltage 380-V three-phase grid. The distribution network grid is modeled as an ideal voltage source with a short-circuit impedance, Zsc (Figure 2). In order to simulate a weak network, a short-circuit impedance is considered for a short-circuit power of $1 \mathrm{MW}$.

In the given system, $\mathrm{Vs}=\mathrm{Vr}=\mathrm{V}$ is considered, where the active power $(\mathrm{P})$ and reactive power $(\mathrm{Q})$ can be found as:

$\mathrm{P}+\mathrm{jQ}=\mathrm{V} \times \mathrm{I}^{*}$

$\mathrm{I}=\mathrm{Y} \times \mathrm{V} \times(1 \angle \beta-1 \angle(\delta-\beta))$

$\mathrm{I}=\mathrm{V} \times\{\mathrm{g} \times(1-\cos \delta)-\mathrm{b} \times \sin \delta+\mathrm{j}[\mathrm{b} \times(\cos \delta-1)-\mathrm{g} \times \sin \delta]\}(3)$

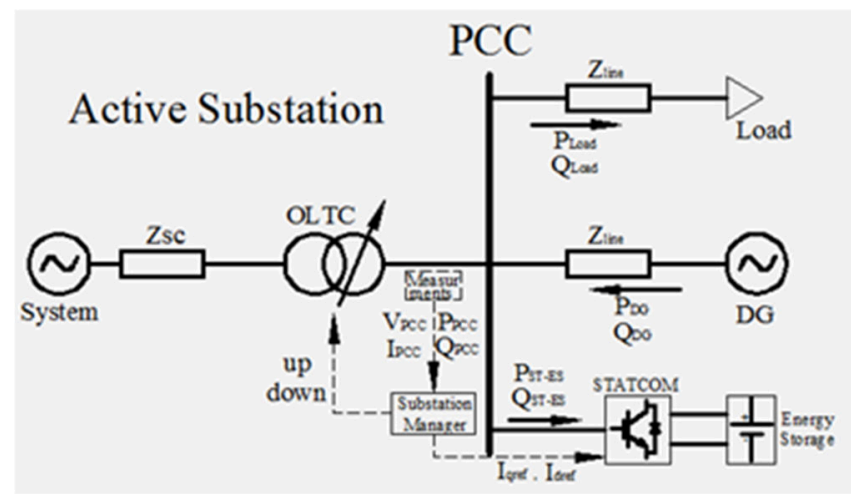

Figure 1. Scheme of the acctive substation.

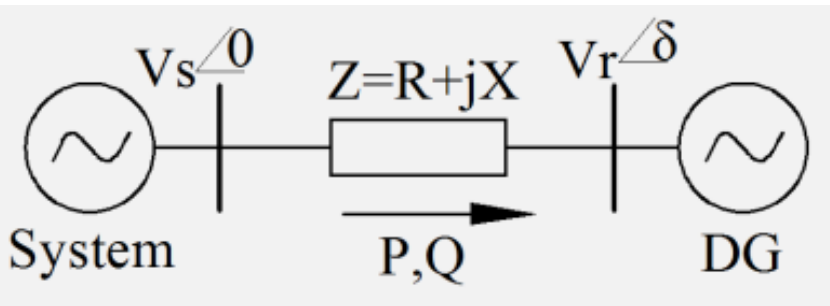

Figure 2. Analytical model of the system.

According to Figure 3, we can write:

$\mathrm{P}=\mathrm{V}^{2} \times[\mathrm{g} \times(1-\cos \delta)-\mathrm{b} \times \sin \delta]$

$\mathrm{Q}=\mathrm{V}^{2} \times[\mathrm{b} \times(1-\cos \delta)+\mathrm{g} \times \sin \delta]$

where,

$\mathrm{P}=$ active power flow from sending end to receiving end $\mathrm{Q}=$ reactive power flow from sending end to receiving end

$\mathrm{B}=\tan ^{-1} \frac{\mathrm{X}}{\mathrm{R}}=$ admittance angle

$\delta=$ voltage angle at receiving end

$\mathrm{Vs}=$ sending end voltage

$\mathrm{Vr}=$ receiving end voltage

$\mathrm{R}=$ equivalent resistance

$\mathrm{X}=$ equivalent inductance

$\mathrm{I}=$ current

$\mathrm{Y}=\frac{1}{\sqrt{\mathrm{R}^{2}+\mathrm{X}^{2}}}=$ admittance

$\mathrm{g}=\frac{1}{\mathrm{R}}=$ real part of admittance

$\mathrm{b}=\frac{1}{\mathrm{x}}=$ imaginary part of admittance

Here, $\mathrm{X}=0.03 \Omega, \mathrm{R}=0.0075 \Omega$ which can be calculated by using the typical $1 \mathrm{MVA} / 20 / 0.38 \mathrm{kV}$ transformer catalog connected to a $20 \mathrm{MVA}, 20 \mathrm{kV}$ distribution system. Figure 4 shows the curves that are obtained from these equations. The voltage angle, active power, and reactive power are variables. By controlling the angle of voltage at DG bus $(\delta)$, it is possible to change the power injection. The $\delta$ can be controlled by Phase Shifting Transformer (PST), and if $\delta$ is increased by $10^{\circ}$, the power injection can be increased up to $0.8 \mathrm{MW}$ 


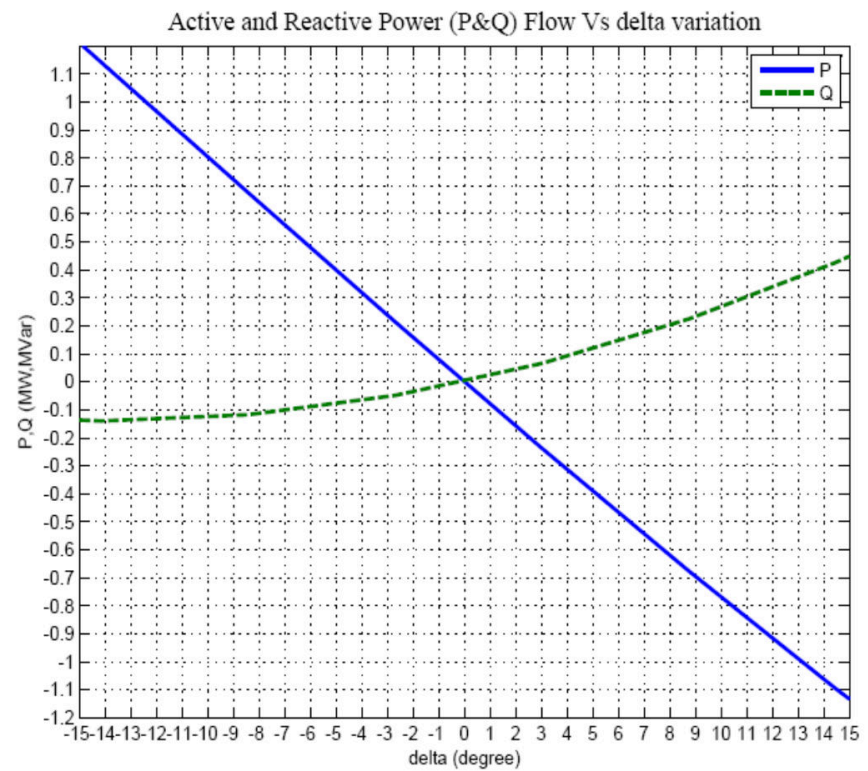

Figure 3. P\&Q Flow Vs $\delta$.

\section{Case study}

One of Afghanistan's existing wind power plants is in Panjshir province, which generates less than $1 \mathrm{MW}$ power when in isolated mode. A $110 \mathrm{KV}$ transmission line and one $110 \mathrm{KV} / 20 \mathrm{KV}$ substation in Panjshir is under construction so that the wind power plant can be promoted to $1 \mathrm{MW}$. When the conversion station is operational, it is important that the domestic grid supply a $1 \mathrm{MW}$ load to match the wind farm's $1 \mathrm{MW}$ power. As the power generation by wind can vary, when the local load demand is low, the wind plant's excess power could be injected to the network. Conversely when wind power is insufficient in meeting demand or the DG is turned-off, energy from the national grid network can meet the demand. The system is simulated under several conditions, and the results are shown below.

\subsection{Programable voltage source as DG (ideal case)}

DG is assumed to work as a programmable voltage source, like a diesel generator or micro hydro plant. When the load demand increases, the generator accelerates to meet the load. When the load demand decreases, the generator should decelerate. Voltage is controlled by generator and is maintained in 1 pu (Ideal Case, Figure 4).

Simulation result without any active device (s):

Results are shown in Figure 5. Here, we can see that the power injection is almost zero ( $1 \mathrm{~kW}$ and $1 \mathrm{kVar}$ only).

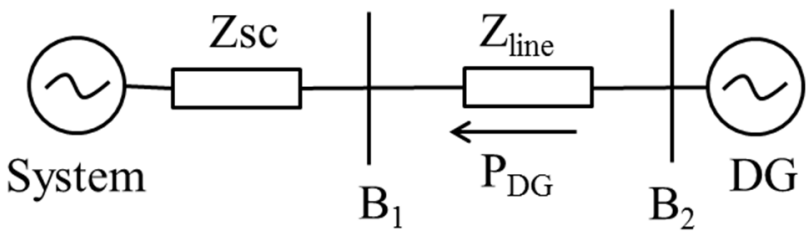

Figure 4. DG integration system without active device and load.
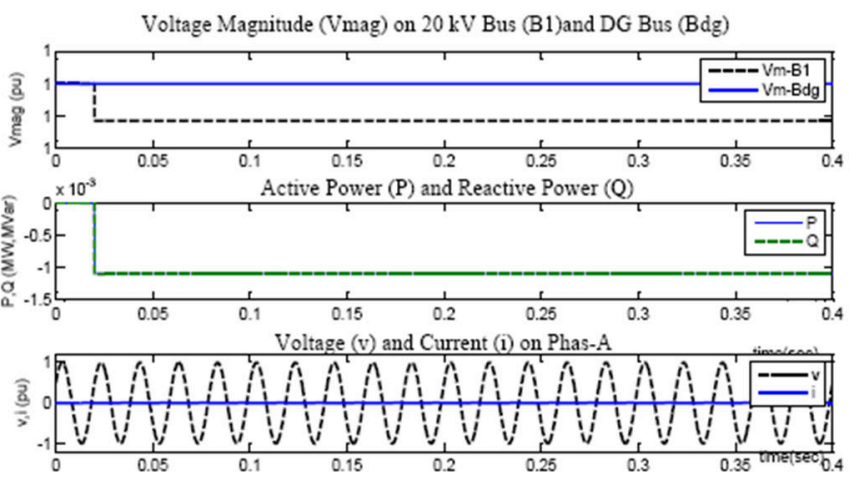

Figure 5. Results of the DG integration system without active device and load.

\subsection{Simulation result with phase shifting transformer (PST) connection}

Connecting the Phase Shifting Transformer (PST) shifts the $\delta$ almost by 3.2 degrees (Figure 6). Results in Figure 7 show that by changing the Tap Position, active power injection changes, but the reactive power is almost constant.

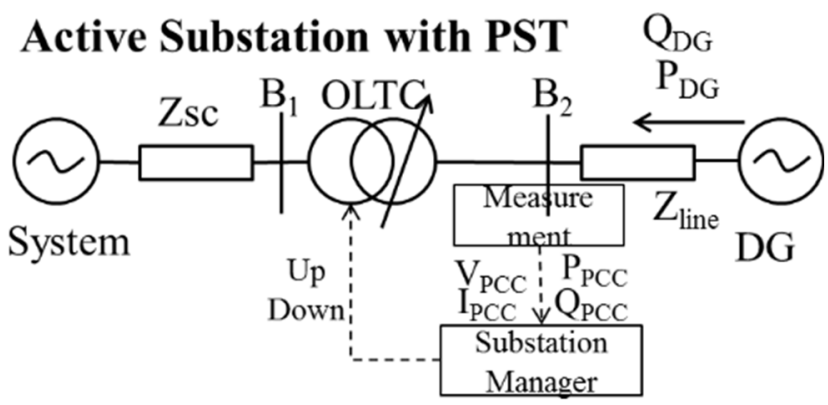

Figure 6. System with PST.
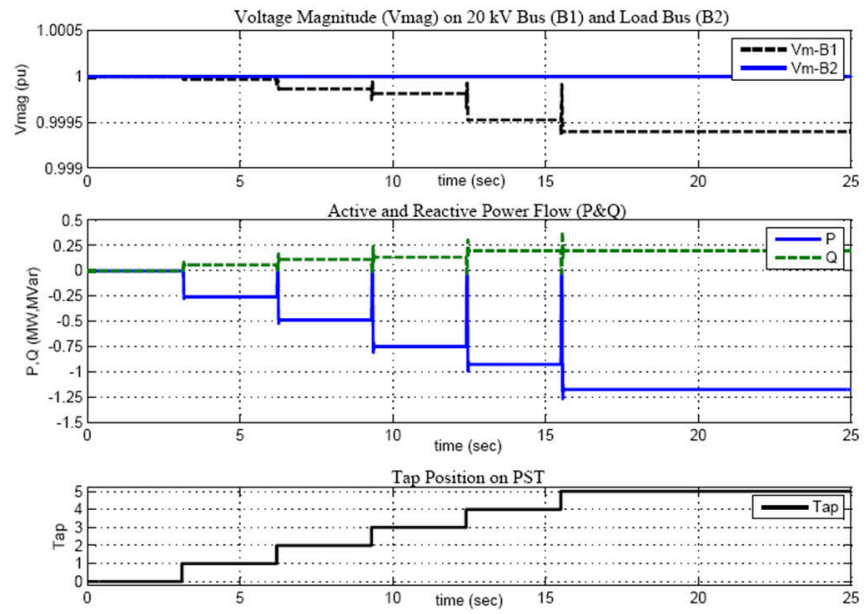

Figure 7. Simulation results with PST depicted in Figure 6.

The system reaches a steady-state condition after 5 steps of Tap Changing. The DG injects active power of about 1.2MW and absorbs reactive power of about $0.2 \mathrm{MVar}$. The 
voltage magnitude in $20 \mathrm{kV}$ Bus, and DG Bus is the same and $1 \mathrm{pu}$.
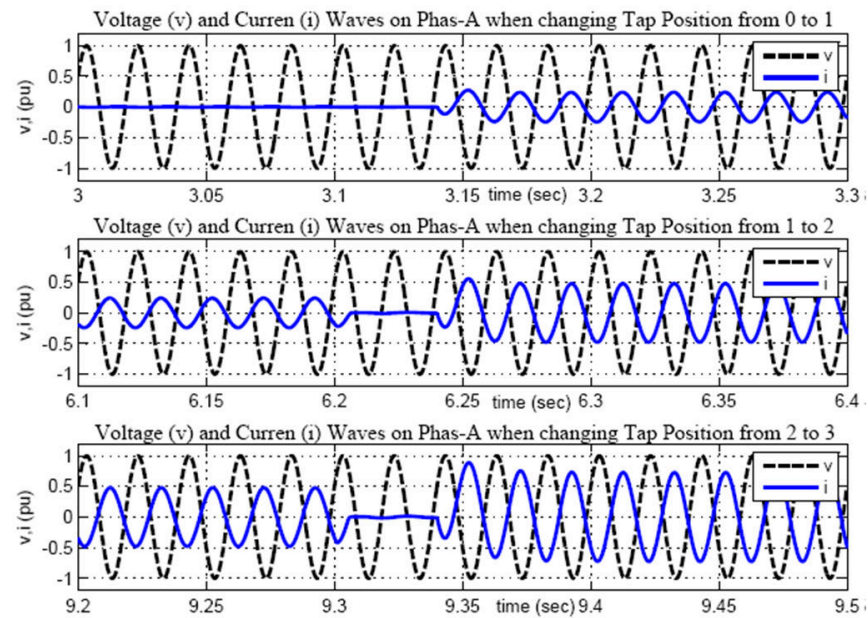

Figure 8. Wave form of voltage and current on phase A when changing tap position

Figure 8 shows that power injection increases by changing the Tap Position and regulating the $\delta$ values. The positive sign shows absorbing power, and negative sign shows injecting power. The DG absorbs a low value of reactive power (Q) but injects a high value of active power to the system. This result almost matches the theoretical analyses that the power injection was increased up to $0.8 \mathrm{MW}$ when $\delta$ was increased by $10^{\circ}$ (with each tap changing, the $\delta$ value is changed by $3.2^{\circ}$ ).

\subsection{Simulation result with PST and 1MVA (0.8MW, 0.6MVar) load}

Both load and PST are connected in Figure 9, with results shown in Figures 10 and 11. In this case, higher than 0.5 MVar of reactive load is supplied by DG and cannot be supplied from the system, since using the Phase Shifting Transformer permits a constant value of the active and reactive power flow in each tap or phase degree. The reactive power supplied by DG may be higher than $Q_{\text {lim }}$ of the DG. Also, DG power generation varies due to seasons or times of day. As a result, for some duration of the time, DG might be off, so the load should by supplied through the network.

Active Substation with PST and Load

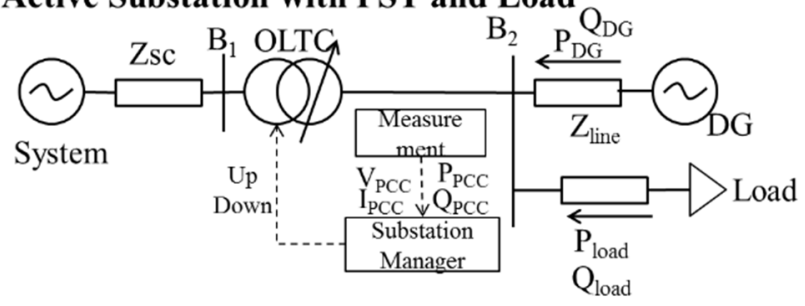

Figure 9. System with PST and load.
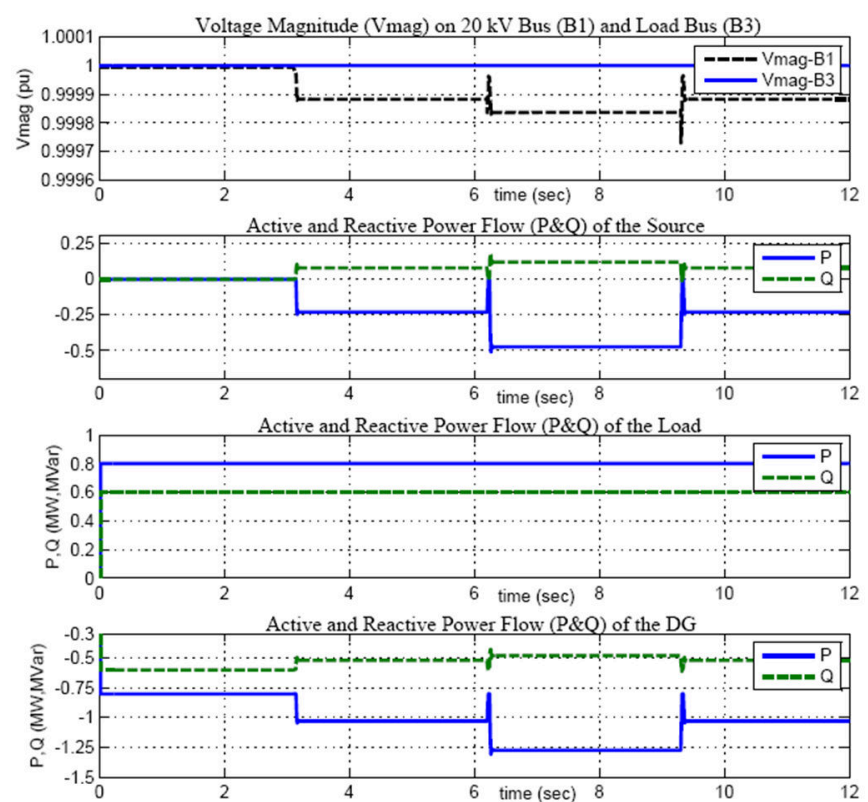

Figure 10. Simulation of active and reactive power with PST and load of $1 \mathrm{MW}(\mathrm{a})$.
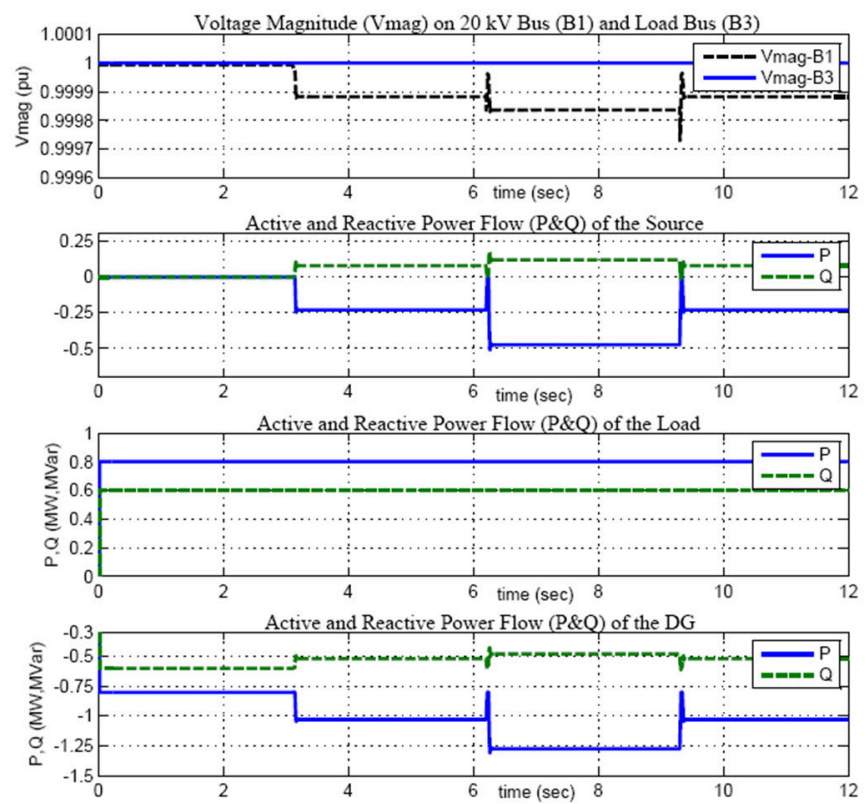

Figure 11. Simulation of active and reactive power with PST and load of $1 \mathrm{MW}(\mathrm{b})$. 

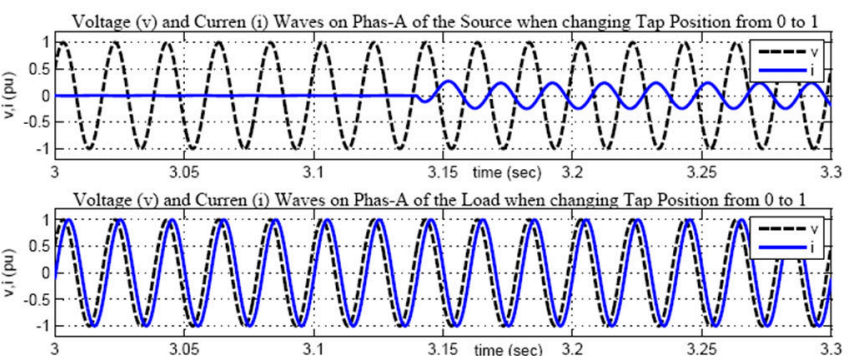

1.5 Voltage (v) and Curren (i) Waves on Phas-A of the DG when changing Tap Position from 0 to 1
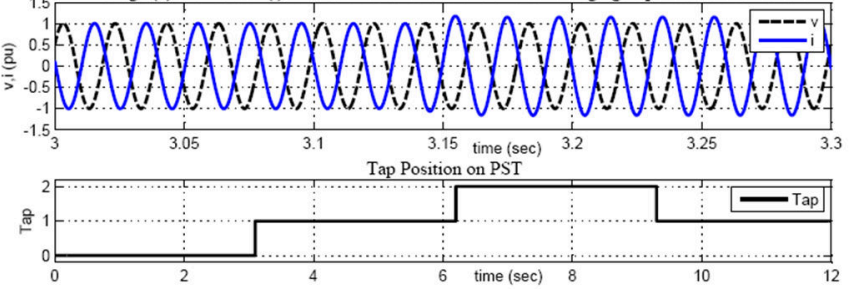

Figure 12. Wave forms of voltage and current with PST and load of 1 MW (a).
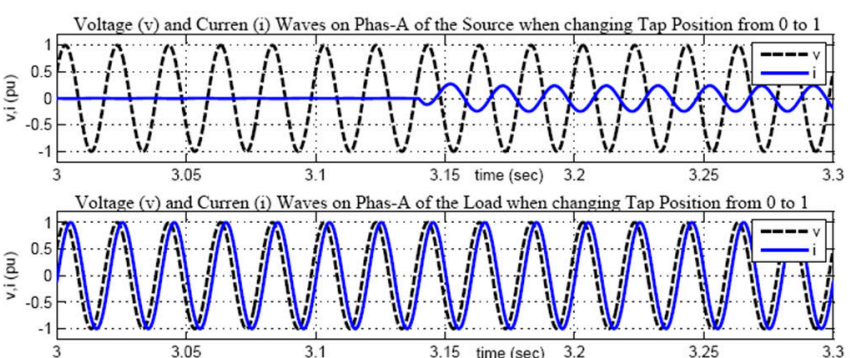

15 Voltage (v) and Curren (i) Waves on Phas-A of the DG when changing Tap Position from 0 to 1
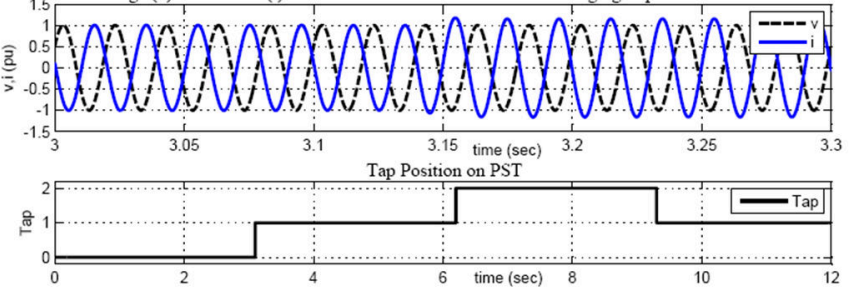

Figure 13. Wave forms of voltage and current with PST and load of 1 MW (a).

\subsection{Simulation result with STATCOM, PST and load}

Figure 12 shows the diagram with PST, load, and STATCOM with results shown in Figures 13 and 14. DG can inject more than $250 \mathrm{KW}$ active power to the system if the capability of DG is high. When the DG capability is only $1 \mathrm{MW}$, it can supply $0.8 \mathrm{MW}$ of load and inject about 250 KW to the system. The reactive power is compensated by STATCOM. The voltage and current wave forms on PhaseA in Figure 14 show that DG absorbs all the harmonics generated by converter.

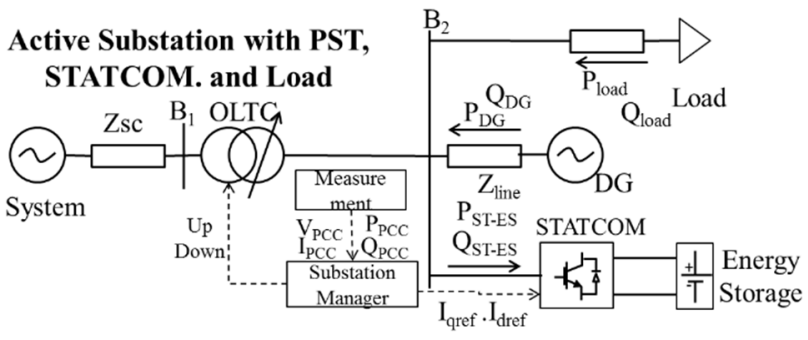

Figure 14. System with PST, STATCOM and load.
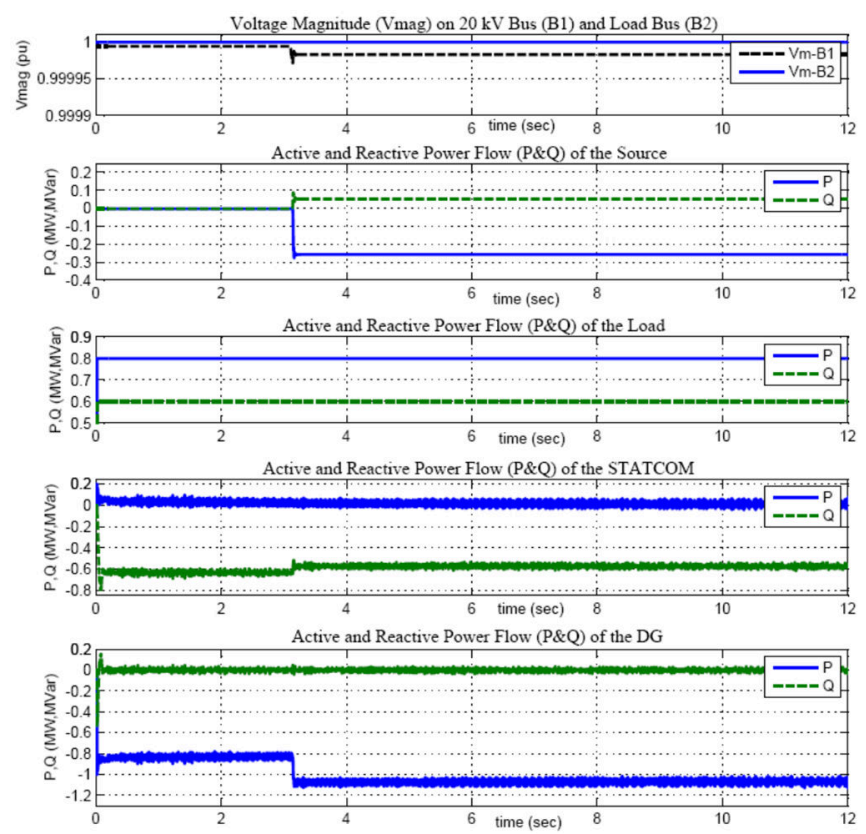

Figure 15. Simulation results with PST, STATCOM, and load.
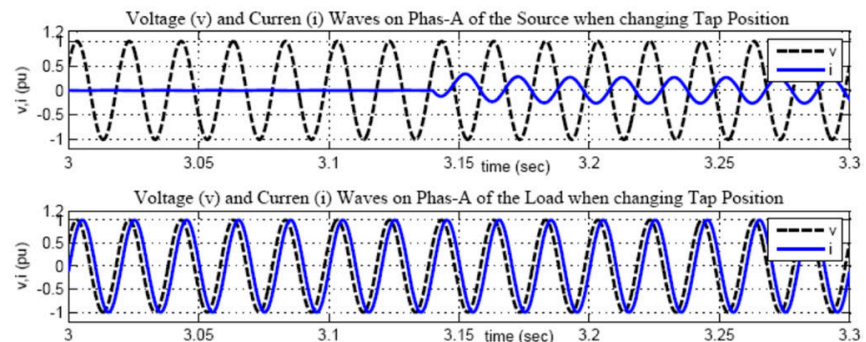

Voltage (v) and Curren (i) Waves on Phas-A of the STATCOM when changing Tap Position

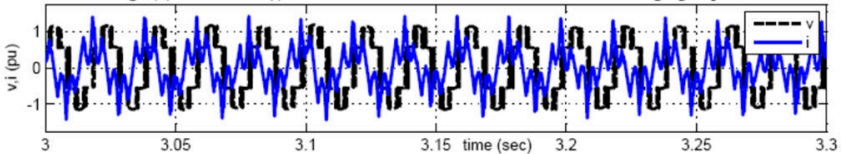

Voltage (v) and Curren (i) Waves on Phas-A of the DG when changing Tap Position
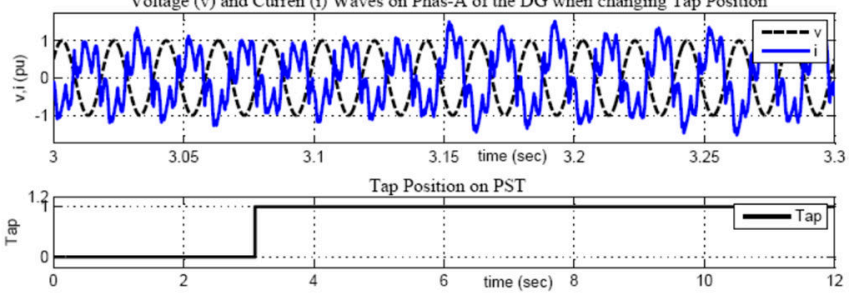

Figure 16. Wave forms of voltage and current with PST, STATCOM, and load. 


\subsection{Wind Power Plant Integration}

Power generation with wind turbines varies with wind speed. With constant load, when the generation is goes up, voltage of DG is increased and vice versa. Voltage should be controlled by increasing or decreasing power injection to the system with the Phase Shifting Transformer. The results are shown in Figures 16 and 17.

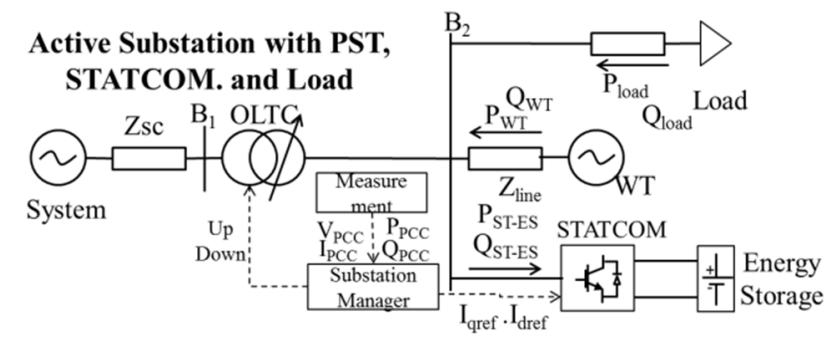

Figure 17. Wind Turbine integration with PST, STATCOM and load.
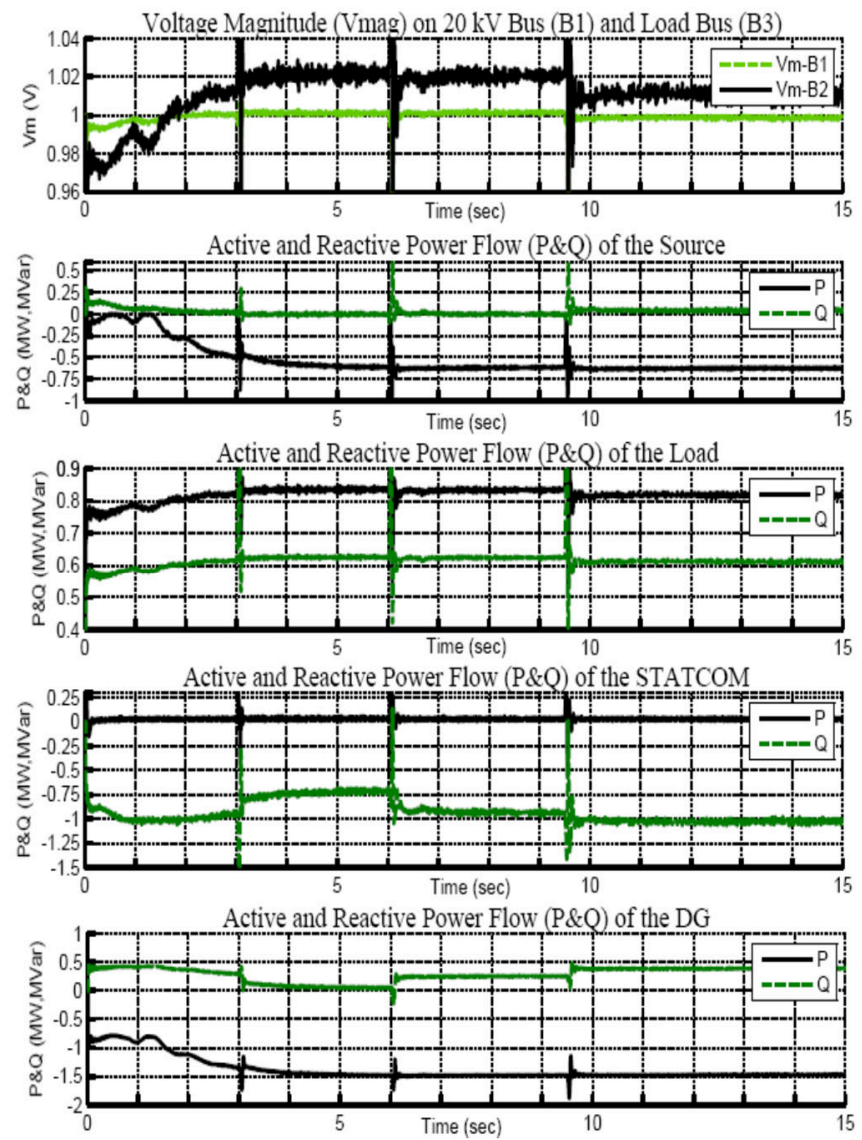

Figure 18. Simulation results of wind turbine integration with PST, STATCOM and load.
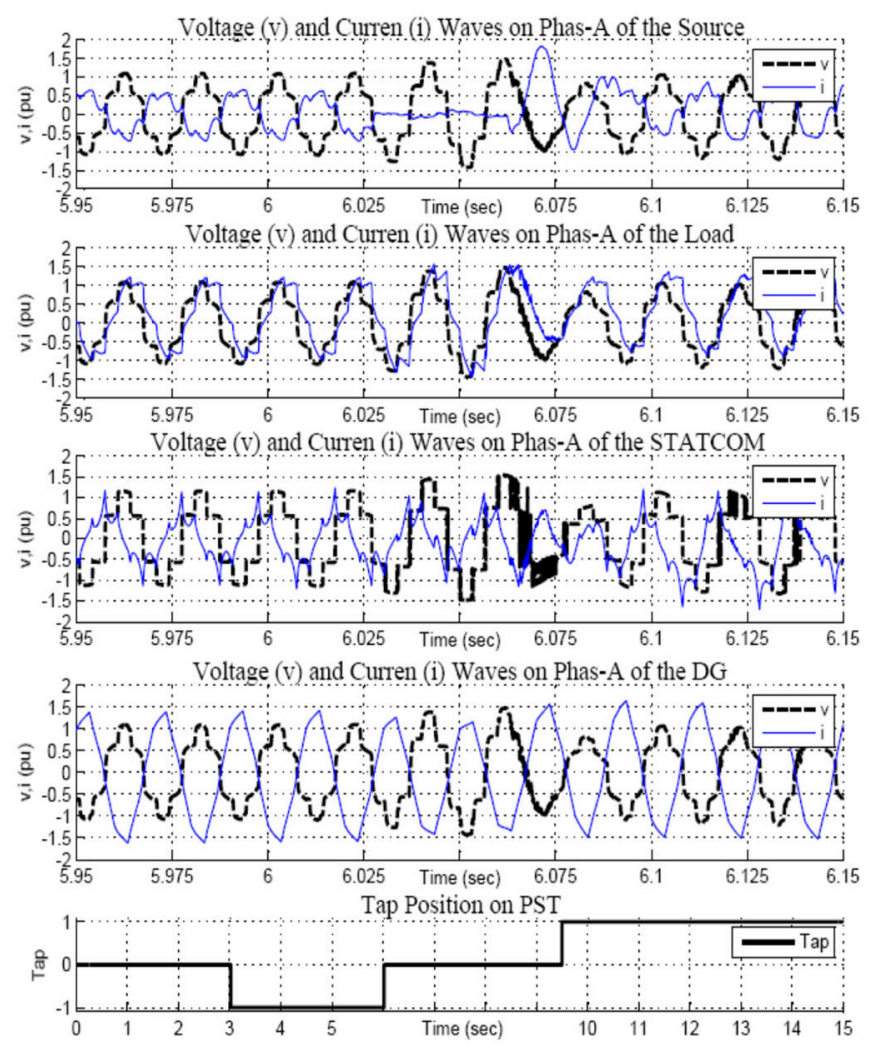

Figure 19. Wave forms of voltage and current with wind turbine integration and with PST, STATCOM and load.

\section{Findings}

Active devices such as PST and STATCOM are widely used for power flow control and reactive load compensation. In this study, these devices can be used for controlling DG power penetration in weak networks as the excess power can be injected in the grid by PST or can charge the storage battery for later usage.

\section{Conclusion}

In this study, managing DG power injection into the domestic grid has been challenging. Active devices should be used can maximize DG power injection into the MV/LV substation. By increasing the DG voltage, more reactive power is injected into the grid; by changing the voltage angle, reactive power is not injected into grid, and active power can be increased or decreased. Reactive power of the load is compensated by STATCOM. Thus, an operation and control strategy for the active substation has been presented, and the performance in a weak grid has been verified by temporal power flow simulations. For future electrical networks where a high amount of electricity can be produced by DG, the use of active devices seems to be necessary to increase active power injection capability in weak networks. In this context, active substations are a suitable solution to increase DG power injection. 


\section{References}

[1] Danish MSS, Senjyu T, Sabory NR, Danish SMS, Ludin GA, et al. (2017) "Afghanistan's aspirations for energy independence: Water resources and hydropower energy" Renewable Energy (vol. 113, pp. 1276-1287) https://doi.org/ 10.1016/j.renene.2017.06.090

[2] Ahmadzai S, McKinna A (2018) "Afghanistan electrical energy and trans-boundary water systems analyses: Challenges and opportunities" Energy Reports (vol. 4, pp. 435469) https://doi.org/10.1016/j.egyr.2018.06.003

[3] Ministry of Energy and Water (MEW) - Afghanistan (2019) "MEW Statistics" (http://mew.gov.af/) Accessed: 4 July 2020

[4] Hallett M (2009) "Distributed power in Afghanistan: The Padisaw micro-hydro project" Renewable Energy (vol. 34, no. 12, pp. 2847-2851) https://doi.org/10.1016/ j.renene.2009.06.001

[5] Martins VF, Borges CLT (2011) “Active Distribution Network Integrated Planning Incorporating Distributed Generation and Load Response Uncertainties" IEEE Transactions on Power Systems (vol. 26, no. 4, pp. 2164-2172) https://doi.org/10.1109/TPWRS.2011.2122347

[6] Verboomen J, Van Hertem D, Schavemaker PH, Kling WL, Belmans R (2005) "Phase shifting transformers: principles and applications" 2005 International Conference on Future Power Systems Amsterdam, Netherlands, IEEE - pp. 1-6. https://doi.org/10.1109/FPS.2005.204302

[7] Siddiqui AS, Khan S, Ahsan S, Khan MI, Annamalai (2012) "Application of phase shifting transformer in Indian Network" 2012 International Conference on Green Technologi -es (ICGT) Trivandrum, India, IEEE - pp. 186-191. https://doi.org/10.1109/ICGT.2012.6477970

[8] El-Moursi MS, Sharaf AM (2005) "Novel controllers for the 48-pulse VSC STATCOM and SSSC for voltage regulation and reactive power compensation" IEEE Transactions on Power Systems (vol. 20, no. 4, pp. 1985-1997) https://doi.org/10.1109/TPWRS.2005.856996

[9] Goikoetxea A, Barrena JA, Rodriguez MA, Abad G (2009) "Active substation design to maximize DG integration" 2009 IEEE Bucharest PowerTech Bucharest, Romania, IEEE - pp. 1-6. https://doi.org/10.1109/PTC.2009.5282156

[10] Rao P, Crow ML, Yang Z (2000) "STATCOM control for power system voltage control applications" IEEE Transactions on Power Delivery (vol. 15, no. 4, pp. 1311-1317) https://doi.org/10.1109/61.891520

[11] Shahzad U, Asgarpoor S (2017) "A Comprehensive Review of Protection Schemes for Distributed Generation" Energy and Power Engineering (vol. 9, no. 8, pp. 430-463) https://doi.org/10.4236/epe.2017.98029

[12] Chetty A, Shoaib M, Sreedevi A (2014) "An Overview of Distributed Generation" International Journal of Modern Engineeirng Research (vol. 4, no. 6, pp. 35-41)

[13] Padiyar KR (2007) "FACTS Controllers in Power Transmission and Distribution," 1st ed. New Delhi, India, New Age International (P) Ltd. p. ISBN: 978-81-224-2541-3

[14] Zayandehroodi H, Mohamed A, Shareef H, Mohammadjafari M (2011) "Distributed Generator and Their Effects on Distribution System Protection Performance" Australian Journal of Basic \& Applied Sciences (vol. 5, no. 10, pp. 398-405) 